\title{
Return to Sport after ACL Reconstruction using Hamstring Tendon: Analyzing 51 Cases from Malta's Hospital in Dakar
}

CVA Kinkpe $^{1 *}$, NPF Ouedraogo ${ }^{2}$, MM Niane $^{1}$, AB Gueye $^{1}$, M Daffe $^{1}$, MM Traore $^{1}$ and GF Ndoye ${ }^{1}$

${ }^{1}$ Orthopaedic Department, Order of Malta's Hospital Center in Dakar, Senegal

2Orthopaedic-Traumatology Department, Blaise COMPAORE Teaching Hospital, Ouagadougou, Senegal

*Corresponding author: CVA Kinkpe, Orthopaedic Department, Order of Malta's Hospital Center in Dakar, Senegal, Tel: +22 1774502646 ; E-mail: cvakinkpe@hotmail.com

Received date: September 22, 2017; Accepted date: December 06, 2017; Published date: December 18, 2017

Copyright: @ 2017 Kinkpe CVA, et al. This is an open-access article distributed under the terms of the Creative Commons Attribution License, which permits unrestricted use, distribution and reproduction in any medium, provided the original author and source are credited.

\begin{abstract}
The anterior cruciate ligament (ACL) rupture is a frequent lesion in athletes. It is incompatible with the practice of high-level sport, especially pivot and contact-pivot ones. The purpose of the ACL reconstruction is to allow the athlete to resume the practice of same sport at the same level.

The study involved 51 sports patients operated for ACL reconstruction at the Order of Malta's Hospital center in Dakar during the period from 1 January 2011 to 31 May 2014. The average age of patients was 26.3 years with a male predominance $(92.15 \%)$. These were professional athletes in $37.25 \%$, amateur in $31.37 \%$, and leisure in $31.37 \%$ of the cases. The sport was contact-pivot in $96.6 \%$ of the cases, mainly football. The objective functional evaluation was performed using the Lysholm-Tegner scale and laximetry using the GNRB arthrometer. The overall sporting recovery rate was $96 \%$ with $54.9 \%$ recovery in the same sport at the same level. Professional athletes were 42 times more likely to resume the same sport at the same level as amateurs. Recovery times were 4.7 months for line sports, 9.2 months for pivot / contact-pivot and 11.3 months for the resumption of competition. These delays were shorter for professionals with a return to pivot sport at 8 months.
\end{abstract}

Apprehension and fear of a new injury were the main reason for sport's downtime or decline. Functional and anatomical results were good with a mean Lysholm score of $91 \%$ and a GNRB differential of 2.87. No independent factor was predictive of returning to sport at the same level.

Returning to sports activity is very likely after an ACL ligamentoplasty, but the return to the same sport at the same level is more uncertain, in the order of $55 \%$ despite satisfactory anatomical and functional results, confirming the important role of other factors such as psychological coaching and sport-specific rehabilitation.

Keywords: Anterior cruciate ligament; Ligamentoplasty; Hamstring tendon; ACL reconstruction

\section{Introductions}

Twenty years ago, the anterior cruciate ligament (ACL) rupture was experienced as a real catastrophe by the athlete and his entourage. The Kenneth Jones technique was considered the "Gold standard' and the sporting return was carried out after one year [1]. Thanks to the techniques improvement and the functional rehabilitation progress, the ACL surgical reconstruction has been "trivialized" in recent years by its wide publicizing [2]. The recovery has gone from one year to six months in developed countries for professional athletes [3].

ACL plays an important role in knee stability [4]. Its disruption leads to a functional disability that is incompatible with sporting pursuits, particularly those of high level [4]. The aim of surgical reconstruction is to allow athletes to return to their pre-injury sporting level, especially for competitors or all those involved in pivot sports [5]. However, in the literature, the good results of validated functional scores do not prejudge the return to sport, which implies the intervention of several other factors [5]. The rates of return to the same sport at the same level are relatively low, around $50 \%$ on average [3]. In black Africa, literature is poor on the ACL plasties in general [6], and on the returning to sport at the same level in particular. Our work was aimed at evaluating the sporty subjects returning to sports after an ACL reconstruction.

\section{Materials and Methods}

This is a retrospective monocentric study covering the period from January 1, 2011, to May 31, 2014. We have consecutively collected all the files of sports patients who benefited from ligamentoplasty during this period. Included were any professional, amateur or recreational sportsperson with MRI-confirmed ACL rupture, with ACL ligamentoplasty in the service and postoperative follow-up of at least one year. The criteria for non-inclusion were lost to follow-up, inoperable records, patients with postoperative follow-up less than one year. The study consisted of 2 parts: The first consisted of collecting epidemiological, anatomo-clinical and therapeutic data on the files. The second consisted in calling the patients to evaluate them. A total of 51 patients took part in the study. These were 47 (92.15\%) men and 4 $(7.85 \%)$ women aged $26.3 \pm 7.4$ years on average. The mean weight was $71.2 \pm 9.9 \mathrm{~kg}$ for an average size of $1.80 \pm 0.1 \mathrm{~m}$, i.e., an average body mass index of $22.0 \pm 2.4 \mathrm{~kg} / \mathrm{m}^{2}$. 
Page 2 of 5

The main type of sport practiced was contact-pivot in $96.6 \%$ and contactless-pivot sport in $3.4 \%$. Concerning the sporting level, these were professional sportsmen in $37.25 \%$, amateurs in $31.37 \%$, and leisure in $31.37 \%$ of the cases. Among the patients, 43 were practicing football, 3 karate, 1 basketball, 1 rugby, 1 wrestling, 1 athleticism and 1 volleyball. The main knee reached was the right in $80.39 \%(n=41)$ of the cases. The dominant knee corresponded to the knee reached in $88.23 \%(\mathrm{n}=45)$ of the cases. ACL rupture was complete in $94.11 \%$ $(n=48)$ of the cases and partial in $5.89 \%(n=3)$. The main associated lesion was the meniscal lesion with $54.9 \%$. The mean time to surgery was $16.8 \pm 19.5$ months. The arthroscopic hamstring graft ligamentoplasty was carried out in $94.11 \%$ of the cases and the technique of Kenneth Jones under arthroscopy in 5.89\% of the cases. Antero-lateral plasty according to Lemaire technique was associated in 2 cases. Simultaneous treatment of the associated lesions was performed in $31.37 \%(n=16)$ of the cases. These were mainly partial meniscectomies and meniscal sutures.

Complications were found in $7.84 \%(n=4)$ of the cases. These were two cases of transplant rerupture, two cases of superficial site infections requiring surgical revision. Functional rehabilitation was performed in all patients. The mean number of sessions was $27.6 \pm$ 11.6. The mean duration of rehabilitation was $10.5 \pm 7.0$ weeks. The functional evaluation was done according to the score of Lysholm and Tegner. The Lysholm scale measures the impact of knee injuries on functional ability. The higher the score, the better your knees are. The Tegner score also gives the result according to the sport practiced. The evaluation of the anterior laxity was made by the GeNouRoB arthrometer. It is the latest generation arthrometer of automatic, millimeter and comparative measurement of anterior laxity assisted by computer. The GNRB system is shown in Figure 1.

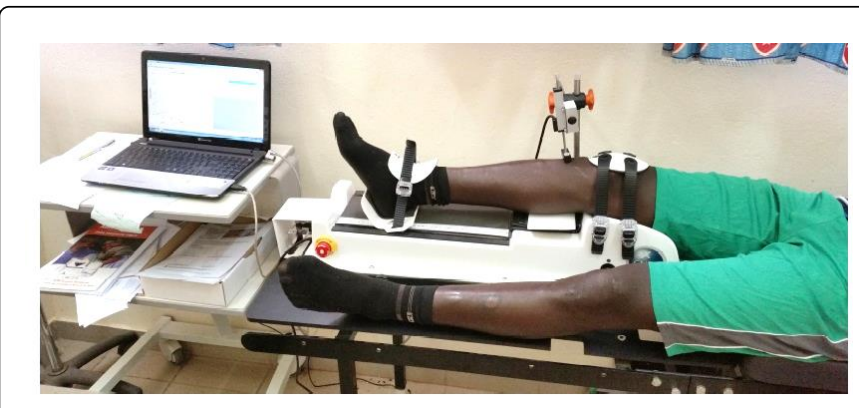

Figure 1: GeNouRoB arthrometer setup.

The patient is lying on a standard examination table in the supine position with the arms placed along the body, each knee being comparatively tested; the healthy knees are investigated first. The lower limb is placed in a single thermoformed support, which does not pose any problem for the installation of different sized adult patients or variation in the positioning of the support. An electric actuator increasing loads according to the examiner: $67,89,134,150$, or $250 \mathrm{~N}$ on the upper aspect of the calf. Testing is repeated on both knees, and the amount of tibial translation is compared between the 2 limbs. Motion data obtained from the displacement transducer produce a force-displacement curve. The slope $(\mathrm{lm} / \mathrm{N})$ of the curve obtained determines the ligamentous elasticity of the patient's ACL. All the data are collected on a remote computer. A laxity file is built up for each patient including measurement conditions (pressure applied to the thigh, load forces) and results (the displacement-load curve, the sideto-side difference in $\mathrm{mm}$ and the slope in $1 \mathrm{~m} / \mathrm{N}$ ).
The data collected were coded, entered and analyzed using Statistical Package for Social Sciences version 20 (SPSS, Chicago, Illinois, USA). The continuous variables have been described on average (standard deviation [SD]) (minimum - maximum); the categorical data in numbers and proportions (n, \%). For the comparison of data, the Student's T-test was used to compare the continuous variables and the test of $\chi^{2}$ or its equivalents to compare the categorical data. A value of $\mathrm{p}<0.05$ was considered statistically significant.

\section{Results}

The mean follow-up was $30.5 \pm 12.2$ months. The overall sports return rate was $96 \%$ for all sports. The different levels of sports return at the last setback is shown in Figure 2. Figure 3 shows the return to the same sport at the same level according to the sports level.

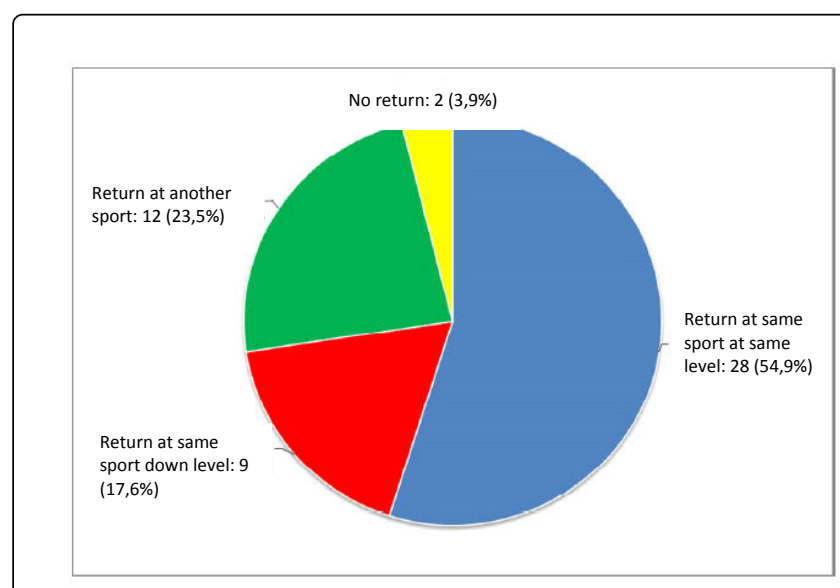

Figure 2: Pie diagram for return levels in sports.

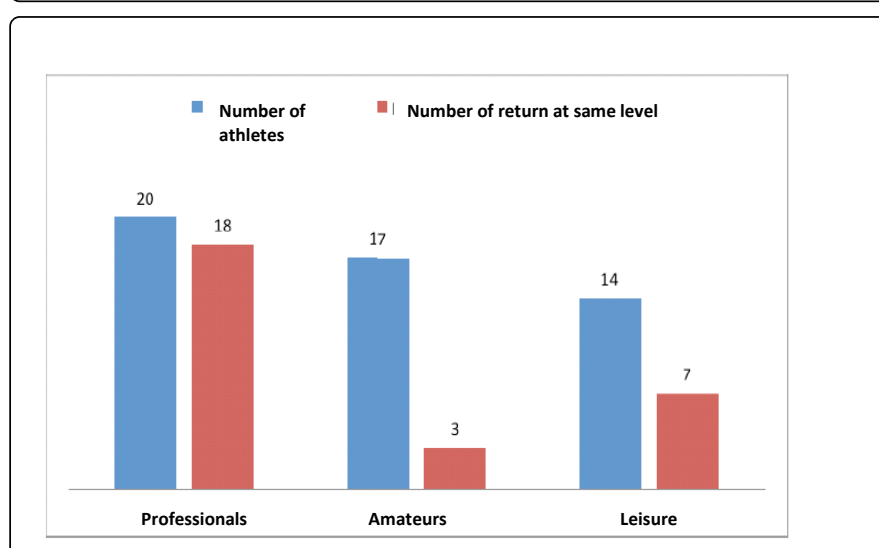

Figure 3: Bar graph representing return to same level as per sport level.

Professional athletes are 42 times more likely to take up the same sport at the same level than amateur athletes and 9 times more than recreational athletes. There is no significant difference in the return to the same sport at the same level between amateur and recreational athletes (Table 1) 
Citation: Kinkpe CVA, Ouedraogo NPF, Niane MM, Gueye AB, Daffe M, et al. (2017) Return to Sport after ACL Reconstruction using Hamstring Tendon: Analyzing 51 Cases from Malta's Hospital in Dakar. J Sports Med Doping Stud 8: 198. doi:10.4172/2161-0673.1000198

Page 3 of 5

\begin{tabular}{|c|c|c|c|}
\hline Parameters & Professional vs. Amateurs & Professional vs. Loisirs & Loisirs vs. Amateurs \\
\hline P-Value & $<0.0001$ & 0.009 & 0.055 \\
\hline OR (IC 95\%) & $42.0(6.5-272.1)$ & $9.0(1.6-51.6)$ & $4.7(0.97-22.6)$ \\
\hline
\end{tabular}

Table 1: Comparison of sporting recovery to the same level as before ACL rupture.

For competitors (amateurs or professionals) the rate of recovery of the competition was $56.7 \%$. Recovery of the competition averaged 11.3 \pm 2.6 months. The average turnaround time for sports was $4.7 \pm 2.6$ months for line sports and $9.2 \pm 4.5$ months for pivot/contact-pivot sports. The turnaround time for the same sport at the same level was $4.3 \pm 2.1$ months for line sports and $8.5 \pm 2.8$ months for pivot / contact-pivot sports. The recovery time according to the sports level before the ACL rupture is shown in Figure 4.

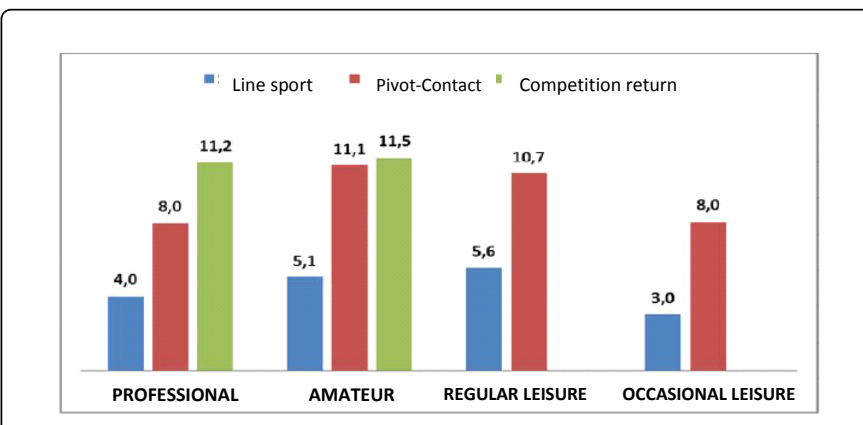

Figure 4: Recovery period (in months) for different sport types based on the sports level before ACL rupture.

The main reasons for stopping sport or competition or changing for a lower level sport are shown in the Figure 5 below.

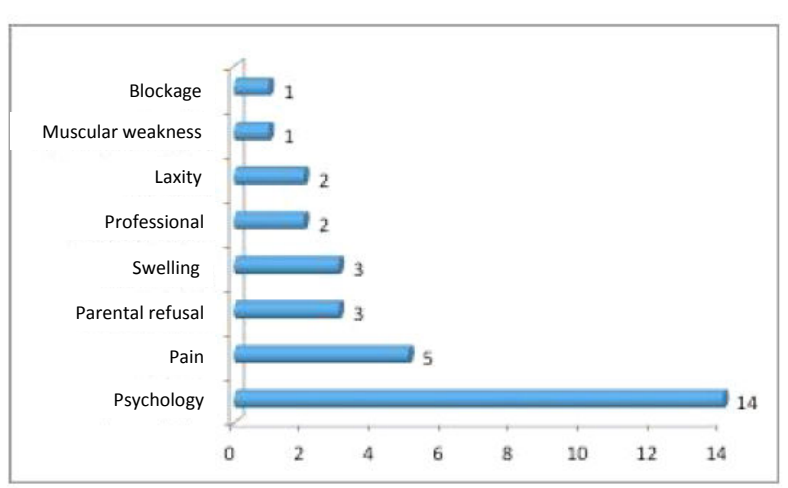

Figure 5: Principal reasons behind stopping or changing the sport.

The pre-rupture and postoperative athletic level according to the TEGNER score returned to an average score of $8.7 \pm 1.2$ before the rupture, and at the last recoil, it was of $7.4 \pm 2.2$. [p<0.0001 with an average difference of 1.35 (95\% CI 0.89-1.82)] (Table 2).

The average LYSHOLM score at last recoil was of $91.8 \pm 6.8 \%$. All patients evaluated had at least a good functional score.
The laximetry was performed in all patients using the GeNouRoB ${ }^{\circ}$ arthrometer. The mean differential of the anterior tibial translation between the two knees was $2.87 \pm 1.76 \mathrm{~mm}$ with extremes ranging from 0.2 to $6.9 \mathrm{~mm}$ against an average preoperative laximetry of $5.58 \pm$ $1.68 \mathrm{~mm}(2.6$ and 7.8$)$.

\begin{tabular}{|l|l|l|l|}
\hline $\begin{array}{l}\text { Periods/Elements of } \\
\text { evaluation }\end{array}$ & $\begin{array}{l}\text { Score de } \\
\text { TEGNER }\end{array}$ & $\begin{array}{l}\text { Score de } \\
\text { Lysolm }\end{array}$ & GNRB \\
\hline Pre-rupture & $8.7 \pm 1.2$ & $74.52 \%$ & $5.58 \pm 1.68 \mathrm{~mm}$ \\
\hline Post operative & $7.4 \pm 2.2$ & $91.8 \pm 6.8 \%$ & $2.87 \pm 1.76 \mathrm{~mm}$ \\
\hline
\end{tabular}

Table 2: Pre-rupture and post-operative averages according to different scores.

In univariate analysis, the following factors influenced the same sport recovery at the same level: age, male, amateur sport, the absence of meniscal lesions, Lysholm score, GNRB $=3$. However, none of these factors is an independent predictive factor for the same sport recovery at the same level (Table 3).

\begin{tabular}{|c|c|c|c|c|}
\hline \multirow[t]{2}{*}{ Factors } & \multicolumn{2}{|c|}{ Univariate analysis } & \multicolumn{2}{|c|}{ Mutivariate analysis } \\
\hline & $\mathbf{P}$ & OR (IC 95\%) & $\mathbf{P}$ & $\begin{array}{c}\text { Ajusted OR (IC } \\
95 \%)\end{array}$ \\
\hline Age, continue* & $<0.001$ & $0.93(0.89-0.97)$ & 0.992 & $0.15(0->99)$ \\
\hline Male sex & $<0.001$ & $0.12(0.04-0.36)$ & 0.995 & $>99(0-0)$ \\
\hline Professional level & 0.999 & $0(0-0)$ & 1 & $0(0-0)$ \\
\hline Amateur level & 0.012 & $0.08(0.01-0.58)$ & 1 & $0(0-0)$ \\
\hline Leisure level & & Ref & & \\
\hline Delay 0 - 12 months & 0.998 & $0.001(0-0)$ & 1 & $0(0-0)$ \\
\hline Delay $13-24$ months & 0.412 & $0.53(0.12-2.41)$ & 1 & $>99(>99->99)$ \\
\hline Delay $>24$ months & & Ref & & \\
\hline No associated lesions & 0.078 & $0.17(0.02-1.22)$ & 1 & $>99(>99$ - >99) \\
\hline No meniscal lesion & 0.015 & $0.17(0.04-0.71)$ & 0.999 & $0(0-0)$ \\
\hline $\begin{array}{l}\text { Lysholm score } \\
\text { continue* }\end{array}$ & $<0.001$ & $0.98(0.96-0.99)$ & 0.994 & $0.01(0-0)$ \\
\hline GNRB $\leq 3$ & 0.011 & $0.10(0.02-0.58)$ & 1 & $0(0-0)$ \\
\hline
\end{tabular}

Table 3: Predictive factors involved in sport recovery. 


\section{Discussion}

Our work on sports recovery after ACL ligamentoplasty in a subSaharan African context is innovative and responds to a real obligation of results in a context where sport has become a major economic issue with the professionalization of local championships. It is therefore imperative to provide a local, clear, fair response based on evidence and local experience to these sportsmen and sports players on the issue of sporting recovery after a breakdown of the ACL. The recent and even current epoch in some of our black African countries, an ACL rupture is synonymous with professional sports career stoppage and end of the young sportsman dreams. Since a sport-specific rehabilitation program was not effective, every sports person had the responsibility, once the surgeon and physiotherapist had given the green light, to do his own rehabilitation. The sports recovery was therefore dependent on many other extrinsic factors, which may be a limit to our work.

Our study shows that $96 \%$ of patients took up any sports practice at a mean follow-up of 30.5 months after ACL ligamentoplasty. This rate is comparable to that of Ardern in Australia (93\% for an average follow-up of 39 months) [7], Gerometta [5] in France (92\% for an average follow-up of 23.7 months). Ardern in a recent meta-analysis including 48 studies in the world or 5770 patients with an average follow-up of 41.5 months regains $82 \%$ of overall sports recovery. These results are superior to those found by Meherzi in Tunisia (52\% for an average follow-up of 42 months) [8].

However, when the same level of sport was recovered, only $55 \%$ of patients had returned to their pre-ACL level. This rate remains comparable to those found in the literature, including Ardern 61\% [7], Kvist 56\% [9], Dauty 53\% [10] and Ardern 63\% [3] in a meta-analysis including 48 recent studies. The authors Gerometta [5] and Meherzi [8] find much lower rates with respectively $38 \%$ and $37 \%$.

However, the vast majority of patients had returned to good, asymptomatic and stable knee function. This discrepancy between the recovery of a quasi-normal knee function and the rate of return to the level before rupture is classically described in the literature and reinforces the idea that other factors intervene in the sporting recovery at the same level [7]. One study found that patients with good postoperative knee function after ACL plasty were not more likely to resume sporting competition at 12 months than those with poor knee function [11].

When we look at the sports recovery at the same level as the prerupture level, it is striking to note the disparity between the different groups: the professionals resumed at the same level in $90 \%$ of the cases, amateurs in only $18 \%$ and recreational athletes in $50 \%$. Professionals were 42 times more likely to resume sport at the same level as amateurs and 9 times as recreational athletes.

Gerometta finds $67 \%$ of professionals, $46 \%$ of amateurs and $31 \%$ of regular recreational sportsmen [5]. Fabricant in a study of the 'Major League' of American baseball professionals found $88 \%$ of recovery at the very high level after ACL plasty [12]. Zaffagnini, who studied professional footballers in Italy, found $95 \%$ of recovery at the preinjury level at 12 months postoperatively [13]. Our results are therefore satisfactory in the light of the literature and confirm that the sports level before the break has a major influence on the sporting recovery [14]. The motivation and supervision of the professional would seem to play an important part in these good results. The absolute desire to find the sport of competition at its best level is the motivation of the professional and the main indication of the intervention realization by the surgeon.

However, in our series, the rate of recovery at the same level among amateurs was very low (18\%). This could be explained by the fact that sport was not a priority for them and had virtually no financial impact, contrasting with the high cost of managing the wound entirely by the patient, and the prospects of earning a living from sport in our context being weak and hypothetical, patients did not find motivation to resume competition with significant risks of injury without social coverage.

Regarding the recovery delay, the overall average recovery time for sport was 4.7 months for line sports and 9.2 months for contact-pivot sports. Recovery delays at the same level were 8.5 months for contactpivot sport. Gerometta in France on a cosmopolitan sports population found a return to the sport of line at 7.6 months and the sport of pivot at 10.2 months. He makes the same observation for the recovery times at the same level which are earlier, 6.6 months and 8.8 months. On the other hand, he finds a period of resumption of the competition at 10.3 months globally and 9.6 months when it comes to the return at the same level [5]. This is shorter than our time of 11.3 months.

When we look at the specific times of recovery according to the sporting level, we see that the higher the level, the shorter the time. The recovery of the pivot-contact sport among professionals was 8 months on average against 11.1 months for amateurs and 10.7 for regular leisure sports. However the time to resume the competition was almost identical and was about 11 months. Gerometta [5] makes much the same observation but with a delay of 2 months shorter than ours. In the same way, Anders in Australia finds a recovery rate of only $33 \%$ to 12 months out of a population of 503 competitors from various contact-pivot sports [11].

On the other hand, Zaffagnini finds in the Italian elite professional footballers a recovery period of the contact-pivot sport of 5.6 months and a return to the competition at 6,2 months on average. Analysis of UEFA's elite football data showed an average return to an official game at 7.5 months for 43 European players [15]. These significantly early timelines could be explained by the quality of rehabilitation program specific to each athlete who has a team of specialists at his disposal given the enormous financial stakes for these top athletes. In addition, the use of early rehabilitation programs in the field (as early as 3 months) with specific sports gestures would reduce the fear of relapse, which is described as an important factor in delayed recovery after ACL plasty [9]. On the other hand, the rehabilitation programs specific to each sportsman are not obvious and the specialists are very few in number, in addition, the sessions are often covered by the sportsman.

Moreover, the preoperative time between the ACL rupture and the reconstruction is very important (on average 16.8 months compared to 1.6 months for Zaffagnini) and could explain the delay in sports recovery because of the "detraining" caused by this long latency time before surgery with its consequences on muscle trophicity, quality of cartilage and meniscus.

The reasons for a drop in level, a change or a stop of the sport were sought in this study. In $45 \%$ of cases, this was a completely independent reason for the knee including psychological reasons (fear of a new injury that was the main reason), parental refusal and professional reasons were found in $16 \%$ of cases. The reasons related to the knee (39\% of cases) were in order: pain, swelling, instability, blockage and muscle weakness. Gerometta also found that fear of a new wound was the main reason [5]. However, Anders finds that more 
than half of patients have not regained their pre-injury level due to an objectively deficient knee [16]. In our study, functional outcomes were generally good in all patients, and in fact did not influence the sports recovery. Even a differential laxity of less than $3 \mathrm{~mm}$ between the healthy knee and the operated knee, reflecting a perfectly stable knee, was not an independent factor for sports recovery. This dichotomy between the satisfactory physical rehabilitation of the knee and the low rate of return to sport of the same level is described in the literature [11]. The factors that will influence the sporting recovery are multiple. The psychological impact on the sports recovery has recently been reported as a determining factor [7]. There is primary evidence that psychological factors would be associated with sports recovery [7]. In studies comparing patients with or without previous sport, there is evidence that low motivation, fear of recidivism and the psychological dimension of sports recovery are associated with the level of sporting recovery. Patients with a higher fear of relapse were less likely to return to pre-rupture levels compared to patients with lesser fear $[9,17]$. Webster [17] and Gerometta [5] in the psychological assessment (confidence, emotions, risk apprehension) of the subjects showed that athletes who resumed sport at their pre-rupture level had a significantly higher score than those who had not recovered at their level. Lack of confidence in oneself or in one's knees, fear of recidivism, an apprehension of resuming the sport with the same level of performance, emotion aroused by the initial trauma or doubts about the sports resumption at the end of rehabilitation are pejorative psychological factors of the sporting recovery. Improving the understanding of psychological factors and opportunity to rectify them is an important issue in the evaluation and optimization of ACL reconstructive surgery. This highlights the need for psychological support for these patients.

\section{Conclusion}

The results of our study show that the return to sports activity is very likely after an ACL reconstruction, of the order of $96 \%$. On the other hand, the return to the same sport at the same level is weaker, despite satisfactory anatomical and functional results, and this rate is superimposable to developed countries series. The pre-break sporting level is a factor influencing the resumption of the same sport at the same level. These low results despite a high rate of success of ligamentoplasty in terms of knee function, laxity and strength, suggest that other parameters such as psychological factors greatly influence the sporting recovery. Our recovery rate at the pre-injury level and our recovery times could be improved by providing psychological support to patients, implementing sports and sports-specific rehabilitation programs, and reducing the waiting times for surgical management that remains very long.

\section{References}

1. Thierry A, Antoine A, Pierre AD, François T (2013) Sports recovery after knee anterior ligamentoplasty. Kinesitherler Scient 0548: 05-15.
2. Gerometta A, Rousseau R, Khiami F, Lutz C (2017) Resumption of sport after ligamentoplasty of the anterior cruciate ligament: Review of the literature. La Médecine du Sport.

3. Ardern CL, Webster KE, Taylor NF, Feller JA (2011) Return to sport following anterior cruciate ligament reconstruction surgery: a systematic review and meta-analysis of the state of play. Br J Sports Med 45: 596-606.

4. Messerli Guy (2007) Reconstruction of the computer-assisted anterior cruciate ligament: prospective non-randomized study with 12-month results of the first 30 cases.

5. Gerometta A, Lutz C, Herman S, Lefèvre N, Dromzee E, et al. (2014) Multicentric french study: Return to sports after anterior cruciate ligament reconstruction in pivot and contact-pivot sports. J Traumatol Sport 31: 171-178.

6. Boire N'Fadama (2004) Study of plasty of the anterior cruciate ligament in the orthopedic surgery and trauma department of the Gabriel Touré hospital in Bamako from January 1999 to June 2004.

7. Ardern CL, Taylor FN, Feller JA, Webster KE (2012) Return-to-sport outcomes at 2 to 7 years after anterior cruciate ligament reconstruction surgery. Am J Sports Med 40: 41-48.

8. Nouri H, Meherzi MH, Charfi H, Ouertatani M, Neji N, et al. (2009) Anatomical reconstruction of the anterior cruciate ligament. Tunisie orthopédique 2: 41-44.

9. Kvist J, Ek A, Sporrstedt K, Good L (2005) Fear of re-injury: A hindrance for returning to sports after anterior cruciate ligament reconstruction. Knee Surg Sports Traumatol Arthrosc 3: 393-397.

10. Dautya M, Le Brun J, Huguet D, Paumier S, Dubois C, et al. (2008) Return to pivot-contact sports after anterior cruciate ligament reconstruction: Patellar tendon or hamstring autografts. Revue de Chirurgie 94: 552-560.

11. Ardern CL, Webster KE, Taylor NF, Feller JA (2010) Return to the preinjury level of competitive sport after anterior cruciate ligament reconstruction surgery two-thirds of patients have not returned by 12 months after surgery. Am J Sports Med 39: 538-543.

12. Fabricant PD, Chin CS, Conte S, Coleman SH, Pearle AD, et al. (2005) Return to play after anterior cruciate ligament reconstruction in Major LeagueBaseball athletes. Arthroscopy 31: 896-900.

13. Zaffagnini S, Grassi A, Marcheggiani Muccioli GM, Tsapralis K, Ricci M, et al. (2014) Return to sport after anterior cruciate ligament reconstruction in professional soccer players. Knee 21: 731-735.

14. Bauer M, Feeley BT, Wawrzyniak JR, Pinkowsky G, Gallo RA (2014) Factors affecting return to play after anterior cruciate ligament reconstruction: A review of the current literature. Phys Sportsmed 42: 71-79.

15. Walden M, Hagglund M, Magnusson H, Ekstrand J (2011) Anterior cruciate ligament injury in elite football: A prospective three-cohort study. Knee Surg Sports Traumatol Arthrosc 19: 11-19.

16. Timothy E (2007) Dynamic neuromuscular analysis training for preventing anterior cruciate ligament injury in female athletes. AAOSInstr Course Lect 56: 397-406.

17. Tripp DA, Stanish W, Ebel-Lam A, Brewer Britton, Birchard J (2007) Fear of reinjury, negative affect, and catastrophizing predicting return to sport in recreational athletes with anterior cruciate ligament injuries at 1 year postsurgery. Rehabil Psycho 52: 74-81. 